\title{
Hearing Thresholds for a Geriatric Population Composed of Korean Males and Females
}

\author{
Junghwa Bahng and Junghak Lee \\ Department of Audiology, Hallym University of Graduate Studies, Seoul, Korea
}

Received April 14, 2015

Revised June 20, 2015

Accepted August 19, 2015
Background and Objectives: The purpose of the present study was to provide the hearing threshold levels in the elderly Korean population, and to compare Korean data with that in the International Organization for Standardization (ISO) 7029 (2000). Subjects and Methods: Data were collected from a total of 526 ears from 112 males and 151 females aged 60-84 years. All participants were screened otologically by the procedure given in ISO 8253-1 (2010). Results: Results showed that the pure-tone average was gradually elevated with increasing age. The amount of hearing loss was greater in males than in females, and the high frequency hearing thresholds were worse than the low frequency hearing thresholds in males and females. The hearing threshold levels were higher at low frequencies in males and at all frequencies in females than the norms of ISO 7029 (2000). Conclusions: Results from this study will be partly used for standardization of hearing thresholds as a function of age in Korea and for updating the ISO 7029.

J Audiol Otol 2015;19(2):91-96

KEY WORDS: Aging · Hearing threshold levels · Presbycusis · Sensorineural hearing loss Pure-tone audiometry.

\section{Introduction}

It is well known that hearing levels progressively deteriorate with age which is the most common factor associated with acquired hearing loss [1]. Age-related hearing loss is prevalent in the elderly regardless of age, gender, or race [2]. The prevalence of hearing loss is more than $50 \%$ in people older than 50 years in the U.S. [3]. In Europe, more than 55\% of males have a hearing loss of more than $30 \mathrm{~dB}$ HL by the age of 80 years [4]. Age-related hearing loss is characterized that high-frequency sounds are more affected than low-frequency sounds. The deterioration of hearing thresholds is mainly due to aging of the peripheral and central auditory system [5] and exposure to environmental noise [6]. The degree of hearing loss varies among individuals, although the degree of hearing loss is larger in males than in females [7].

The age-related variation in hearing thresholds was defined

This is an Open Access article distributed under the terms of the Creative Commons Attribution Non-Commercial License (http://creativecommons. org/licenses/by-nc/3.0/) which permits unrestricted non-commercial use, distribution, and reproduction in any medium, provided the original work is properly cited. by International Organization for Standardization (ISO) 7029 [8], providing the expected hearing threshold distribution in population aged from 18 to 70 years. However, ISO 7029 was based upon the hearing thresholds for European and North American populations between the 1950s and the 1970s [9]. Some authors have indicated the problems with ISO 7029 in terms of specific population data, subject selection criteria, outdated calibration and test procedures, and restricted test frequencies. Authors have proposed to revise the norms of hearing thresholds as a function of age [10-12], and as a result, ISO 7029 is currently under revision by the ISO technical committee 43 .

This research is an extension of the study by Lee, et al. [13]. In that study, 2492 adults (1250 males and 1242 females) with an age range of $20-59$ years who were otologically normal were included. Approximately 30 male and 30 female subjects were selected within each age band. The primary goal of this study is to provide the distribution of hearing thresholds as a function of age in Korean individuals from 60 to 84 years of age who have been screened by the procedure described in the ISO 8253-1 [14]. The hearing threshold levels in this study were compared with those provided by the 
ISO 7029. Also, the hearing thresholds for each signal frequency according to gender and age groups were compared. We anticipate that these data will be used for preparing new standards of hearing thresholds as a function of age in Korea and for updating the ISO 7029 under revision.

\section{Subjects and Methods}

\section{Subjects}

Data were collected from a total of 526 ears (from 112 males and 151 females aged $60-84$ years). The age criteria were stratified into $60-64,65-69,70-74,75-79$, and $80-84$ groups in 5-year intervals as shown in Table 1. All subjects were recruited from various areas in Korea (Seoul, Chuncheon, Gwangju, Daegu, and Mokpo) in order to ensure sampling from the entire country. All of the participants received an A-type tympanogram and did not report a history of hearing loss, ear surgery, otologic disease, or occupational noise exposure (ISO 8253-1, 2000).

\section{Audiometric condition}

Audiometric tests were conducted by trained audiologists. A GSI 61 audiometer (Grason-Stadler, Eden Prairie, MN, USA) was used for measuring pure-tone thresholds in a soundproof room. According to the criteria of ISO 8253-1, the maximum permissible sound pressure level for ambient noise in the room was sufficiently low. The test tones were calibrated first by the method of ISO 389-5 and 389-8 and then presented to participants through TDH-50 headphones (Telephonics, Farmingdale, NY, USA). A sound level meter (Type 2250-L; B\&K, Denmark) was used for the calibrations with a microphone (Type 4192; B\&K) and a preamplifier (Type 2690-A-0S1; B\&K).

\section{Procedure}

Informed consent was obtained from the participants and a questionnaire was additionally completed before audiometric tests. Both ears were tested, and the first ear (right or left) was chosen randomly in all subjects. If hearing thresholds in right

Table 1. The number of ears of subjects (males and females) according to the 5-year age band

\begin{tabular}{ccc}
\hline Age band (year) & Males (ears) & Females (ears) \\
\hline $60-64$ & 39 & 53 \\
$65-69$ & 49 & 90 \\
$70-74$ & 57 & 66 \\
$75-79$ & 47 & 61 \\
$80-84$ & 26 & 28 \\
\hline Total & 218 & 298 \\
\hline
\end{tabular}

and left ears differed by more than $20 \mathrm{~dB}$ HL at a given frequency, only better hearing thresholds in the ear were obtained. Pure-tone air conduction audiometry was conducted over the range of $250-8000 \mathrm{~Hz}$ in the order of 1000,2000 , $3000,4000,6000,8000,500$, and $250 \mathrm{~Hz}$ with a combined ascending and descending approach following a standardized protocol (ISO 8253-1). An audiologist presented stimuli, and the participants were asked to press a button when they heard any beep sound.

\section{Statistical analyses}

The data were analyzed using SPSS version 17.0 (IBM Inc., Armonk, NY, USA). The hearing thresholds for each signal frequency for each age band were compared by gender using an independent $\mathrm{t}$-test. The dependent variable was the hearing thresholds for the frequencies, and the independent variable was gender. To compare average hearing thresholds in each age band for males and females, one-way analysis of variance (ANOVA) was conducted. The between factor was each age band, and the independent variable was average hearing threshold. A $p<0.05$ was accepted as the level of statistical significance. Also, alpha coefficients of ISO 7029 and Korean data were compared. ISO 7029 presents the equation $\Delta \mathrm{H}_{\mathrm{md}}$, $\mathrm{Y}=\alpha(\mathrm{Y}-18 \text { years })^{2}$ for computing the expected age-related hearing loss. $\Delta \mathrm{H}$ refers to the deviation from the median hearing threshold level at an age of $\mathrm{Y}$ years based on a reference age of 18 years $(0 \mathrm{~dB} \mathrm{HL})$. We applied this equation to calculate the alpha coefficients $\left(\mathrm{dB} /\right.$ years $\left.^{2}\right)$.

\section{Results}

\section{Hearing threshold levels compared by gender and age band}

Table 2 lists the numerical data related to the hearing threshold distributions $\left(5^{\text {th }}, 10^{\text {th }}, 25^{\text {th }}\right.$, median, $75^{\text {th }}, 90^{\text {th }}$, and $95^{\text {th }}$ percentiles) for males and females in each age band. The results of the independent t-test showed that there were no significant differences between genders in low frequencies (250 and $500 \mathrm{~Hz}$ ), but there were significant differences in high signal frequencies. Table 3 provides a summary of the statistical information.

The average hearing thresholds were computed by averaging the hearing sensitivity at 500,1000 , and $2000 \mathrm{~Hz}$ (Table 4), and 4000, 6000, and $8000 \mathrm{~Hz}$ (Table 5). For comparing the mean hearing thresholds of each age band, one-way ANOVA was conducted. The independent variable was the average hearing thresholds and the between factor was the age band. Results of mean thresholds of 500, 1000, and 2000 $\mathrm{Hz}$ revealed that there were significant differences among the 
Bahng J, et al.

Table 2. Numerical data of hearing threshold distributions $\left(5^{\text {th }}, 10^{\text {th }}, 25^{\text {th }}\right.$, median, $75^{\text {th }}, 90^{\text {th }}$, and $95^{\text {th }}$ percentiles and mean) for males and females in each age band

\begin{tabular}{|c|c|c|c|c|c|c|c|c|c|c|c|c|c|c|c|c|c|}
\hline \multirow{2}{*}{\multicolumn{2}{|c|}{ Age band (yr) }} & \multicolumn{8}{|c|}{ Male $(\mathrm{Hz})$} & \multicolumn{8}{|c|}{ Female $(\mathrm{Hz})$} \\
\hline & & \multirow{2}{*}{$\begin{array}{r}250 \\
5.0\end{array}$} & \multirow{2}{*}{$\begin{array}{r}500 \\
5.0\end{array}$} & \multirow{2}{*}{$\begin{array}{r}1000 \\
5.0\end{array}$} & \multirow{2}{*}{$\begin{array}{r}2000 \\
5.0\end{array}$} & \multirow{2}{*}{$\begin{array}{r}3000 \\
5.0\end{array}$} & \multirow{2}{*}{$\begin{array}{r}4000 \\
5.0\end{array}$} & \multirow{2}{*}{$\frac{6000}{15.0}$} & \multirow{2}{*}{$\begin{array}{r}8000 \\
10.0\end{array}$} & \multirow{2}{*}{$\begin{array}{l}250 \\
10.0\end{array}$} & \multirow{2}{*}{$\begin{array}{l}500 \\
10.0\end{array}$} & \multirow{2}{*}{$\begin{array}{l}1000 \\
10.0\end{array}$} & \multirow{2}{*}{$\begin{array}{r}2000 \\
0.0\end{array}$} & \multirow{2}{*}{$\begin{array}{r}3000 \\
5.0\end{array}$} & \multirow{2}{*}{$\begin{array}{r}4000 \\
5.0\end{array}$} & 6000 & 8000 \\
\hline & P5 & & & & & & & & & & & & & & & 10.0 & 15.0 \\
\hline & $\mathrm{P} 10$ & 5.0 & 5.0 & 5.0 & 10.0 & 10.0 & 10.0 & 20.0 & 20.0 & 15.0 & 10.0 & 10.0 & 5.0 & 10.0 & 10.0 & 15.0 & 20.0 \\
\hline & P25 & 5.0 & 10.0 & 10.0 & 15.0 & 15.0 & 20.0 & 5.0 & 35.0 & 15.0 & 15.0 & 15.0 & 10.0 & 15.0 & 15.0 & 20.0 & 30.0 \\
\hline & Med & .0 & 15.0 & 20.0 & 20.0 & 25.0 & 30.0 & 5.0 & 45 & 20.0 & 20.0 & 15.0 & 15.0 & 20.0 & 20.0 & 35.0 & 40.0 \\
\hline & P75 & 5.0 & 25.0 & 25.0 & 30.0 & 35.0 & 76.0 & . & 55 & 25.0 & 25.0 & 20.0 & 25.0 & 30.0 & 30.0 & 45.0 & 55.0 \\
\hline & $\mathrm{P} 90$ & 0.0 & 35.0 & 35.0 & 35.0 & 50.0 & 60.0 & 70.0 & 70.0 & 30.0 & 30.0 & 25.0 & 30.0 & 35.0 & 40.0 & 55.0 & 70.0 \\
\hline & P95 & 5.0 & 35.0 & 40.0 & 35.0 & 65.0 & 70.0 & 80.0 & 80.0 & 30.0 & 30.0 & 30.0 & 35.0 & 35.0 & 40.0 & 60.0 & 75.0 \\
\hline & & 19.0 & 17.7 & 19.2 & 21.8 & 27.9 & 33.7 & 42.2 & 45.3 & 20.0 & 18.6 & 17.5 & 18.3 & 20.8 & 23.6 & 34.6 & 42.8 \\
\hline & $S D$ & 9.0 & 10.0 & 9.6 & 9.4 & 15.5 & 18.3 & 19.0 & 18.5 & 5.7 & & 6.6 & 10.2 & 9.6 & 11.8 & 15.4 & 18.2 \\
\hline & P5 & 5.0 & 5.0 & 5.0 & 5.0 & 10.0 & 10.0 & 20.0 & 25.0 & 10.0 & 10.0 & 5.0 & 5.0 & 10.0 & 10.0 & 20.0 & 15.0 \\
\hline & P10 & 10.0 & 5.0 & 5.0 & 10.0 & 10.0 & 15.0 & 20.0 & 30.0 & 10.0 & 10.0 & 10.0 & 10.0 & 10.0 & 10.0 & 20.0 & 20.0 \\
\hline & P25 & 10.0 & 10.0 & 10.0 & 10.0 & 15.0 & 25.0 & 30.0 & 40.0 & 15.0 & 15.0 & 10.0 & 15.0 & 15.0 & 15.0 & 25.0 & 30.0 \\
\hline & Med & 20.0 & 15.0 & 15.0 & 20.0 & 30.0 & 40.0 & 45.0 & 55.0 & 20.0 & 20.0 & 20.0 & 20.0 & 20.0 & 25.0 & 35.0 & 45.0 \\
\hline & P75 & 25.0 & 25.0 & 25.0 & 30.0 & 40.0 & 55.0 & 55.0 & 65.0 & 25.0 & 25.0 & 25.0 & 25.0 & 30.0 & 35.0 & 45.0 & 55.0 \\
\hline & P90 & 30.0 & 30.0 & 30.0 & 35.0 & 55.0 & 60.0 & 65.0 & 75 & 30.0 & 30.0 & 30.0 & 35.0 & 40.0 & 45.0 & 65.0 & 70.0 \\
\hline & P95 & 30.0 & 30.0 & 35.0 & 40.0 & 55.0 & 60 & 70.0 & 80 & 30.0 & 35.0 & 35 & $4 C$ & 4 & 50.0 & 70.0 & 80.0 \\
\hline & Mea & 18.0 & 18.0 & 18.5 & 21.2 & 29.9 & 38.3 & 45.5 & 53 & 19.3 & 19.7 & 19.6 & 21.1 & 23.6 & 26.6 & 38.5 & 44.9 \\
\hline & $S D$ & 8.2 & 9.0 & 9.8 & 11.1 & 14.5 & 17 & 16.4 & 17 & 7.6 & 1 & 8.9 & 10.4 & 12.8 & 12.5 & 16.2 & 18.2 \\
\hline & P5 & 10.0 & 5.0 & 5.0 & 10.0 & 10.0 & 25.0 & 30.0 & 40 & 10.0 & 15.0 & 10.0 & & 5 & 10.0 & 0 & 25.0 \\
\hline & P10 & 10.0 & 10.0 & 10.0 & 15 & 20.0 & 25 & 40.0 & 45 & 15.0 & & 10 & & & & & .0 \\
\hline & P25 & 20.0 & 15.0 & 20.0 & 20.0 & 25 & 35.0 & 45.0 & & & & & & & & & 5.0 \\
\hline & Med & 25.0 & & & & 35.0 & 50 & & & & & & & & & & .0 \\
\hline & P75 & & & & & & & & & & & & & & & & \\
\hline & P90 & & & 40.0 & 45.0 & & & & & & & & & & & & 0 \\
\hline & P95 & & & & 55 & & & & & & & & & & & & 90.0 \\
\hline & Mea & & 23.2 & & $2 \varepsilon$ & & & & & & & & & & & & .4 \\
\hline & $S D$ & & 10. & & 12 & & & & & & & & & & & 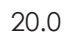 & .8 \\
\hline & P5 & 10.0 & 10.0 & 10.0 & 10.0 & 15.0 & 20 & 35.0 & 40 & 10.0 & 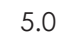 & 15 & 10 & 10 & 15.0 & 20.0 & 20.0 \\
\hline & P10 & 10.0 & 10.0 & 10.0 & 15.0 & 20.0 & 25.0 & 40.0 & 45 & 15.0 & 15.0 & 15.0 & 15.0 & 15.0 & 20.0 & 25.0 & 35.0 \\
\hline & P25 & 20.0 & 15.0 & 20.0 & 20.0 & 30.0 & 35.0 & 45.0 & 55 & 20.0 & 20.0 & 20.0 & 20.0 & 20.0 & 25.0 & 40.0 & 50.0 \\
\hline & Med & 25.0 & 25.0 & 25.0 & 30.0 & 40.0 & 50.0 & 60.0 & 65.0 & 25.0 & 25.0 & 25.0 & 25.0 & 30.0 & 35.0 & 50.0 & 60.0 \\
\hline & P75 & 35.0 & 35.0 & 35.0 & 40.0 & 60.0 & 65.0 & 70.0 & 85.0 & 30.0 & 35.0 & 35.0 & 40.0 & 45.0 & 50.0 & 65.0 & 70.0 \\
\hline & P90 & 40.0 & 40.0 & 50.0 & 55.0 & 65.0 & 75.0 & 80.0 & 85.0 & 35.0 & 40.0 & 40.0 & 45.0 & 55.0 & 60.0 & 70.0 & 80.0 \\
\hline & P95 & 45.0 & 45.0 & 55.0 & 60.0 & 70.0 & 75.0 & 80.0 & 90.0 & 35.0 & 40.0 & 45.0 & 50.0 & 55.0 & 65.0 & 75.0 & 85.0 \\
\hline & Mea & 26.3 & 25.0 & 28.7 & 32.7 & 42.6 & 49.9 & 59.4 & 65.6 & 24.9 & 26.9 & 26.7 & 28.8 & 32.5 & 36.1 & 50.2 & 57.8 \\
\hline & SD & 10.9 & 11.8 & 13.5 & 15.5 & 17.4 & 18.2 & 15.1 & 18.3 & 8.4 & 10.3 & 11.3 & 12.9 & 14.8 & 16.2 & 17.0 & 18.2 \\
\hline $80-84$ & P5 & 15.0 & 10.0 & 5.0 & 10.0 & 20.0 & 30.0 & 35.0 & 40.0 & 15.0 & 15.0 & 10.0 & 15.0 & 20.0 & 20.0 & 25.0 & 30.0 \\
\hline & P10 & 15.0 & 10.0 & 15.0 & 10.0 & 25.0 & 30.0 & 35.0 & 50.0 & 20.0 & 20.0 & 10.0 & 20.0 & 20.0 & 20.0 & 30.0 & 30.0 \\
\hline & P25 & 20.0 & 20.0 & 20.0 & 25.0 & 35.0 & 40.0 & 50.0 & 55.0 & 25.0 & 20.0 & 20.0 & 25.0 & 25.0 & 30.0 & 45.0 & 57.5 \\
\hline & Med & 30.0 & 35.0 & 40.0 & 35.0 & 47.5 & 50.0 & 60.0 & 62.5 & 30.0 & 25.0 & 30.0 & 35.0 & 37.5 & 45.0 & 55.0 & 70.0 \\
\hline & P75 & 35.0 & 40.0 & 45.0 & 50.0 & 55.0 & 60.0 & 70.0 & 75.0 & 40.0 & 37.5 & 37.5 & 45.0 & 50.0 & 57.5 & 65.0 & 75.0 \\
\hline & P90 & 40.0 & 45.0 & 45.0 & 55.0 & 65.0 & 65.0 & 75.0 & 85.0 & 45.0 & 45.0 & 45.0 & 50.0 & 55.0 & 60.0 & 75.0 & 80.0 \\
\hline & P95 & 40.0 & 45.0 & 50.0 & 70.0 & 75.0 & 75.0 & 75.0 & 85.0 & 45.0 & 45.0 & 45.0 & 50.0 & 60.0 & 65.0 & 75.0 & 85.0 \\
\hline & Mean & 28.5 & 29.8 & 33.7 & 35.8 & 45.8 & 50.6 & 58.1 & 64.6 & 31.1 & 28.6 & 27.9 & 34.1 & 37.0 & 42.1 & 53.8 & 63.9 \\
\hline & SD & 9.4 & 12.1 & 13.3 & 17.1 & 16.4 & 15.0 & 13.0 & 13.3 & 8.8 & 10.2 & 12.1 & 11.2 & 13.5 & 15.9 & 15.2 & 17.2 \\
\hline
\end{tabular}


Table 3. Summary of independent t-test results for the gender comparison

\begin{tabular}{cccc}
\hline Frequency & $\dagger$ & Degree of freedom & p-value \\
\hline 250 & -0.081 & 514 & 0.935 \\
500 & -0.549 & 416.842 & 0.583 \\
1000 & 2.011 & 416.268 & 0.045 \\
2000 & 2.801 & 514 & 0.005 \\
3000 & 6.508 & 412.276 & $<0.001$ \\
4000 & 8.776 & 420.807 & $<0.001$ \\
6000 & 6.415 & 514 & $<0.001$ \\
8000 & 4.838 & 514 & $<0.001$ \\
\hline
\end{tabular}

Table 4. Mean thresholds of 500,1000 , and $2000 \mathrm{~Hz}$ for males and females

\begin{tabular}{lrrrrr}
\hline \multirow{2}{*}{ Gender } & \multicolumn{5}{c}{ Age band } \\
\cline { 2 - 6 } & $60-64$ & $65-69$ & $70-74$ & $75-79$ & $80-84$ \\
\hline Male & & & & & \\
Mean & 19.57 & 19.22 & 25.56 & 28.79 & 33.08 \\
SD & 9.71 & 10.01 & 11.51 & 13.91 & 14.38 \\
Female & & & & & \\
Mean & 18.11 & 20.11 & 23.86 & 27.46 & 30.18 \\
SD & 8.09 & 9.17 & 10.70 & 11.52 & 11.42 \\
\hline
\end{tabular}

SD: standard deviation

Table 5. Mean thresholds of 4000,6000 , and $8000 \mathrm{~Hz}$ for males and females

\begin{tabular}{lccccc}
\hline \multirow{2}{*}{ Gender } & \multicolumn{5}{c}{ Age band } \\
\cline { 2 - 6 } & $60-64$ & $65-69$ & $70-74$ & $75-79$ & $80-84$ \\
\hline Male & & & & & \\
$\quad$ Mean & 40.38 & 45.71 & 56.93 & 58.30 & 57.76 \\
$\quad$ SD & 19.10 & 17.95 & 17.85 & 18.34 & 14.79 \\
Female & & & & & \\
$\quad$ Mean & 33.68 & 36.67 & 41.57 & 48.01 & 53.26 \\
SD & 17.19 & 17.50 & 21.41 & 19.27 & 18.28 \\
\hline
\end{tabular}

SD: standard deviation

age bands for males $[\mathrm{F}(4,213)=12.042, p<0.001]$ and for females $[\mathrm{F}(4,293)=15.760, p<0.001]$. Results of mean thresholds of 4000,6000, and $8000 \mathrm{~Hz}$ also showed that there were significant differences among the age bands for males $[\mathrm{F}(4$, $213)=12.478, p=0.000]$ and for females $[F(4,293)=15.760$, $p=0.000]$. For the post hoc test, bonferroni method was used. Table 6 and Table 7 provide summary of post hoc tests for mean thresholds of 500, 1000, $2000 \mathrm{~Hz}$ and those of 4000 , $6000,8000 \mathrm{~Hz}$, respectively.

\section{Age-related hearing threshold distributions in males and females compared with ISO 7029}

Table 8 presents the mean alpha coefficient values for the present study and those for ISO 7029 at each signal frequency for males and females. Figs. 1 and 2 show the mean hearing thresholds of each age band for the males and females.
Table 6. Summary of post hoc tests for average hearing thresholds $(500,1000,2000 \mathrm{~Hz})$ in males and females

\begin{tabular}{|c|c|c|c|c|c|}
\hline Age band & $60-64$ & $65-69$ & $70-74$ & $75-79$ & $80-84$ \\
\hline \multicolumn{6}{|l|}{ Male } \\
\hline $60-64$ & & & & * & * \\
\hline $65-69$ & & & * & * & * \\
\hline $70-74$ & & & & & $*$ \\
\hline \multicolumn{6}{|l|}{$75-79$} \\
\hline \multicolumn{6}{|l|}{$80-84$} \\
\hline \multicolumn{6}{|l|}{ Female } \\
\hline $60-64$ & & & $*$ & $*$ & $*$ \\
\hline $65-69$ & & & & $*$ & $*$ \\
\hline $70-74$ & & & & & * \\
\hline \multicolumn{6}{|l|}{$75-79$} \\
\hline $80-84$ & & & & & \\
\hline
\end{tabular}

Table 7. Summary of post hoc tests for average hearing thresholds $(4000,6000,8000 \mathrm{~Hz})$ in males and females

\begin{tabular}{|c|c|c|c|c|c|}
\hline & $60-64$ & $65-69$ & $70-74$ & $75-79$ & $80-84$ \\
\hline \multicolumn{6}{|l|}{ Male } \\
\hline $60-64$ & & & $*$ & $*$ & $*$ \\
\hline $65-69$ & & & * & $*$ & * \\
\hline $70-74$ & & & & & $*$ \\
\hline \multicolumn{6}{|l|}{$75-79$} \\
\hline \multicolumn{6}{|l|}{$80-84$} \\
\hline \multicolumn{6}{|l|}{ Female } \\
\hline $60-64$ & & & $*$ & $*$ & $*$ \\
\hline $65-69$ & & & & * & $*$ \\
\hline $70-74$ & & & & & $*$ \\
\hline $75-79$ & & & & & \\
\hline $80-84$ & & & & & \\
\hline
\end{tabular}

The smooth curves correspond to age-related hearing loss. Since ISO 7029 does not provide hearing thresholds according to age bands, the median hearing thresholds at each age were computed by the equation and means of the hearing thresholds for each age band were calculated for comparison. Results revealed that the elderly Korean population had worse hearing thresholds than the estimated hearing thresholds based on the ISO 7029 equation applied to the same age band. In particular, Korean males had similar hearing thresholds at high frequencies and worse hearing thresholds at low frequencies than those based on the ISO 7029. Korean females had worse hearing thresholds at all frequencies than those based on the ISO 7029. 
Table 8. Alpha coefficents $(\alpha)$ for males and females across signal frequencies

\begin{tabular}{lccccc}
\hline Sex & Frequency $(\mathrm{Hz})$ & $\mathrm{a}$ (mean) & $\mathrm{SD}$ & $95 \% \mathrm{Cl}$ & $\alpha$ (ISO 7029) \\
\hline Male & 250 & 0.0081 & 0.0035 & $0.0046-0.0055$ & 0.0030 \\
& 500 & 0.0079 & 0.0038 & $0.0039-0.0049$ & 0.0035 \\
& 1000 & 0.0086 & 0.0041 & $0.0040-0.0051$ & 0.0040 \\
& 2000 & 0.0096 & 0.0045 & $0.0020-0.0032$ & 0.0070 \\
& 3000 & 0.0127 & 0.0059 & $0.0004-0.0020$ & 0.0115 \\
& 4000 & 0.0156 & 0.0067 & $-0.0013-0.0005$ & 0.0160 \\
& 6000 & 0.0187 & 0.0066 & $-0.0001-0.0016$ & 0.0180 \\
& 8000 & 0.0209 & 0.0067 & $-0.0020--0.0002$ & 0.0220 \\
& 250 & 0.0083 & 0.0030 & $0.0050-0.0056$ & 0.0030 \\
& 500 & 0.0082 & 0.0032 & $0.0044-0.0051$ & 0.0035 \\
& 1000 & 0.0080 & 0.0035 & $0.0036-0.0044$ & 0.0040 \\
& 2000 & 0.0086 & 0.0043 & $0.0022-0.0031$ & 0.0060 \\
& 3000 & 0.0096 & 0.0048 & $0.0016-0.0027$ & 0.0075 \\
& 4000 & 0.0109 & 0.0053 & $0.0013-0.0025$ & 0.0090 \\
& 6000 & 0.0154 & 0.0065 & $0.0027-0.0042$ & 0.0120 \\
\end{tabular}

ISO: International Organization for Standardization, Cl: confidential Interval, SD: standard deviation

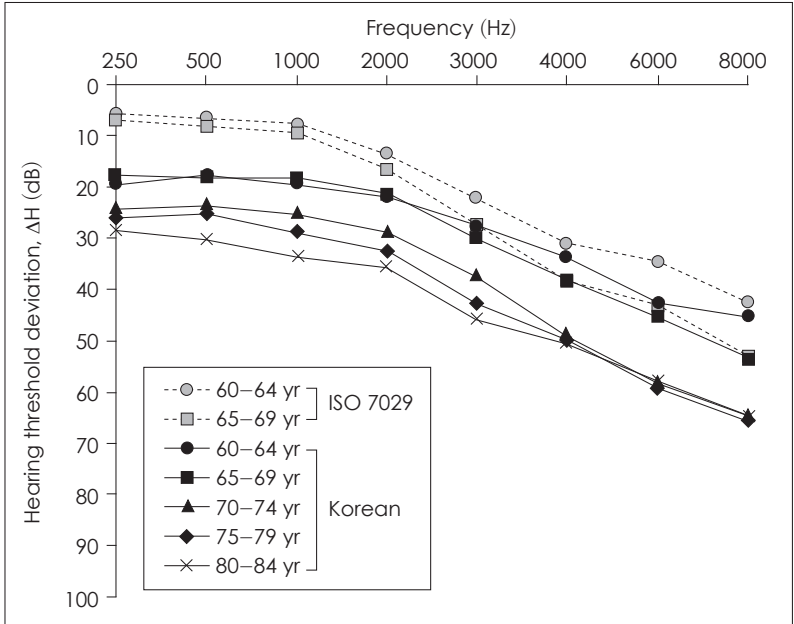

Fig. 1. Mean hearing threshold distribution in Korean males and that based on the ISO 7029. ISO: International Organization for Standardization.

\section{Discussion}

\section{Age-related hearing loss compared by gender and age band}

Table 2 lists the numerical data of hearing threshold distributions for the male and female participants. Additionally, Figs. 1 and 2 show the mean hearing thresholds for both male and female participants. Hearing thresholds increased at all frequencies with increasing age in the older Korean population. These patterns were consistent with ISO 7029 as well as with those in previous studies $[10,12,15,16]$.

A previous study showed that significant differences between genders occurred between 3000 and $8000 \mathrm{~Hz}$ [16]. In

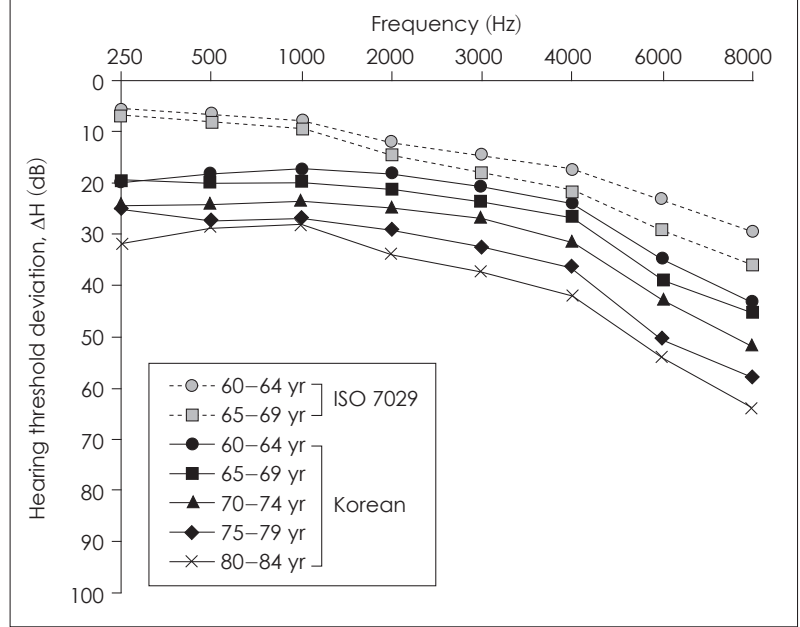

Fig. 2. Mean hearing threshold distribution in Korean females and that based on the ISO 7029. ISO: International Organization for Standardization.

the present study, hearing thresholds across age bands in males were significantly higher than those in females from 1000 to $8000 \mathrm{~Hz}$. We also found that pure-tone threshold averages (PTAs) of low (500, 1000, and $2000 \mathrm{~Hz}$ ) and high frequencies $(4000,6000$, and $8000 \mathrm{~Hz})$ were gradually elevated in males as compared to those in females with increasing age. Again, greater PTA differences in high frequencies were observed in males than in females. This excessive noise exposure is one of the main reasons of elevated hearing-frequency hearing loss [17]. Most Korean males of 60 years and above were required to serve in the military for at least 21 months. However, we did not assess whether each individual had experience of military service. Recent studies have reported that 
noise-induced hearing loss and tinnitus were increased due to noise exposure during military service [18]. Therefore, it is possible that exposure to excessive noise during military service affected the elevated hearing sensitivity of Korean males.

\section{Comparison of hearing thresholds in Korean population with those in the ISO 7029}

Results revealed higher alpha coefficients in males than in females at most frequencies. Furthermore, the alpha coefficients were larger at high frequencies than at low frequencies. Taken together, these results suggest a greater amount of age-related hearing loss in males than in females and more hearing loss at higher frequencies than at lower frequencies. Compared with the alpha coefficients of the ISO 7029, the alpha coefficients of the present study were higher for both genders except for high frequencies in males. In particular, the alpha coefficients of the present study for both males and females at low frequencies were higher than those of the ISO 7029. These results are consistent with previous studies [10,16]. In the study by Wiley, et al. [16], the hearing sensitivity for individuals aged 48-65 years was compared with the ISO 7029 median thresholds for males and females. The results revealed that the expected hearing thresholds based on the ISO 7029 were better than those in the previous data. The differences between the data and the ISO values were larger for males than for females. In the study by Stenklev and Laukli [10], alpha coefficients were significantly higher than the ISO values, especially at $125-4000 \mathrm{~Hz}$, for females. Our results also indicated that the differences between the data and the ISO values were larger for females across all frequencies.

\section{Conclusion}

In conclusion, we presented the data of hearing thresholds for a Korean screened population aged from 60-84. It is difficult to compare our data directly with those of previous studies due to differences in sample size, age range, and etc. However, similar general findings were observed. We conclude that 1) hearing threshold sensitivity increases with age, 2) greater hearing losses at high frequencies appear across all age groups, and 3) greater hearing losses are seen in males than in females. As discussed above, these data will be used for establishing a new Korean standard with data from 2003
[13] and for updating the ISO 7029 which is presently under revision.

\section{Acknowledgments}

This research was sponsored by a grant from the Korean Ministry of Trade, Industry \& Energy (Project No. 10049456).

\section{REFERENCES}

1) Bielefeld EC, Tanaka C, Chen GD, Henderson D. Age-related hearing loss: is it a preventable condition? Hear Res 2010;264:98-107.

2) Lin FR, Thorpe R, Gordon-Salant S, Ferrucci L. Hearing loss prevalence and risk factors among older adults in the United States. J Gerontol A Biol Sci Med Sci 2011;66:582-90.

3) Hilton C, Huang T. Age-Related Hearing Loss. Geriatr Aging 2008; 11:522-4.

4) Roth TN, Hanebuth D, Probst R. Prevalence of age-related hearing loss in Europe: a review. Eur Arch Otorhinolaryngol 2011;268:1101-7.

5) Ouda L, Profant O, Syka J. Age-related changes in the central auditory system. Cell Tissue Res 2015;361:337-58.

6) Strauss S, Swanepoel DW, Becker P, Eloff Z, Hall JW 3rd. Noise and age-related hearing loss: a study of 40123 gold miners in South Africa. Int J Audiol 2014;53 Suppl 2:S66-75.

7) Wiley TL, Chappell R, Carmichael L, Nondahl DM, Cruickshanks KJ. Changes in hearing thresholds over 10 years in older adults. J Am Acad Audiol 2008;19:281-92; quiz 371.

8) International Organization for Standardization. Acoustics-Statistical distribution of hearing thresholds as a function of age. Geneva: ISO 7029;2000.

9) Robinson DW, Sutton GJ. Age effect in hearing - a comparative analysis of published threshold data. Audiology 1979;18:320-34.

10) Stenklev NC, Laukli E. Presbyacusis-hearing thresholds and the ISO 7029. Int J Audiol 2004;43:295-306.

11) Williams W, Carter L, Seeto M. Hearing threshold levels for a population of 11 to 35 year old Australian females and males. Int J Audiol 2014;53:289-93.

12) Kurakata K, Mizunami T, Matsushita K, Shiraishi K. Air conduction hearing thresholds of young and older Japanese adults for pure tones from $125 \mathrm{~Hz}$ to $16 \mathrm{kHz}$. Acoust Sci Tech 2011;32:16-22.

13) Lee JH, Kim JS, Oh SY, Kim KS, Cho SJ. Effects of age on hearing thresholds for normal adults. Korean J Audiol 2003;7:15-23.

14) International Organization for Standardization. Acoustics-Audiometric test methods-Part 1: Basic pure tone air and bone conduction threshold audiometry. Geneva: ISO 8253-1;2010.

15) Kim TS, Chung JW. Evaluation of age-related hearing loss. Korean J Audiol 2013;17:50-3.

16) Wiley TL, Torre P 3rd, Cruickshanks KJ, Nondahl DM, Tweed TS. Hearing sensitivity in adults screened for selected risk factors. $\mathrm{J}$ Am Acad Audiol 2001;12:337-47.

17) Labarère J, Lemardeley P, Vincey P, Desjeux G, Pascal B. [Acute acoustic trauma in military personnel. Evaluation of 1 year epidemiologic surveillance]. Presse Med 2000;29:1341-4.

18) Lee JE, Kim K, Bahng J. The Relationship of Tinnitus Handicap and Health Status Measured by SF-36 in Discharged Soldiers. Audiol 2014;10:208-22. 